\title{
Dog bite as a public health concern in Addis Ababa
}

\author{
Fasil Mengistu ${ }^{1}$, Kedir Hussen ${ }^{1}$, Abraham Ali $^{1}$, Goroma Getahun ${ }^{1}$, Dessalegn Sifer $^{1}$
}

\begin{abstract}
Introduction: Animal bites and scratches represent the most important public health issue related to dogs and cats because of the risk of rabies transmission associated with physical, psychological trauma and wound infection. Objective: The study was aimed at estimating the prevalence of animal bite of human beings in Addis Ababa.

Methods: Data on the kind of animal, age of the patients, gender, site of bites and /or scratch were collected from the registry book and analyzed using SPSS version 11.5.

Results: A total of 1299 cases of bite and/or scratch were reported for the period September 2008 to August 2009. The majority of bites were made by dogs where stray dogs are much higher $\left(\mathrm{X}^{2}=0.83, \mathrm{p}=0.36\right)$. There is statistically highly significant difference of bites between sex $(\mathrm{p}=0.001)$ and between age group $(\mathrm{F}=5.41, \mathrm{p}=0.02)$. The animal bite made by dogs was higher on legs $(55.6 \%)$ followed by hands $(26.45 \%)$ and multiple bites $(7.51 \%)$.

Conclusions: The majority of bites were attributed to stray dogs followed by cats, horses, donkeys. To reduce the problem a preventative public education is suggested. [Ethiop. J. Health Dev. 2011;25(1):58-60]
\end{abstract}

\section{Introduction}

The threat of animal attacks on people is still a huge medico-social problem as these attacks result in millions of injuries and thousands of deaths all over the world (1). According to a WHO report, ten million people are bitten by animals around the world, considered for prophylaxis and treatment against rabies and almost 50,000 people die from this disease annually (2). Dogs have shared their lives with humans for more than 12,000 years, and this coexistence has contributed substantially to humans' quality of life (3). In many families, dogs play an important role in security, as companions, and friends. Unfortunately, this partnership is not without problems. In recent years, it has become more and more apparent that dog bites are a serious and often underestimated public health problem (4). Bites and scratches related to dogs and cat represent the most important public health concern because of the associated physical and psychological trauma, they cause wound infection by different microorganisms and the risk of rabies transmission (5).

In Addis Ababa where dogs are the commonest domestic animal, the total dog population and the number of stray dogs are estimated to be 250,000 and 120,000 respectively according to the Urban Agriculture Extension Core process, 2005 cited by Abraham et al., 2010. In this city the high rate of cases was well established with no decline in the annual number of confirmed rabid dogs in the year 2003 to 2009 (6). The study was aimed at the manifestation of animal bite of human beings in Addis Ababa, during the period between September 2008 and 2009.

\section{Methods}

A retrospective study was conducted in humans who were reportedly bitten and scratched by animals from September 2008 to August 2009 in Addis Ababa, Ethiopia. Data were gathered from the registry book on various characters that included the kind of animal causing the bite, and the bitten humans subjects regarding the age, site of bite and /or scratch and other important variables as recorded by the Zoonoses Diseases Research Laboratory of Ethiopian Health and Nutrition Research Institute. Human Patients' name, initials, address, hospital identification and other personal records were not mentioned in this study and are kept confidential for ethical reasons. Data were entered in excel spread sheet and analyzed in SPSS version 11.5. Descriptive statistics, Chi square test and one way ANOVA were computed as necessary.

\section{Results}

During the study period, 1299 cases of exposure to animal bite and/or scratch have been reported. The mean annual bite and/or scratch were $2.44 \pm 1.33$. Dogs, cats, other animals such as (donkeys, horses, hyenas, and cows) and monkeys were the common species causing bites (Table 1). There was a statistically highly significant difference among animal kinds $\left(\mathrm{X}^{2}=5289.28\right.$, $\mathrm{p}=0.001)$. The majority of bites were caused by stray $\operatorname{dogs}\left(\mathrm{X}^{2}=0.83, \mathrm{p}=0.36\right)$. 
Table 1: Animal bites and /or scratches of humans related to animal species in Addis Ababa during September 2008 to August 2009.

\begin{tabular}{ll}
\hline Animal kind & Bite and/or scratch (\%) \\
\hline Dog & \\
Owned & $526(40.5 \%)$ \\
Stray & $699(53.8 \%)$ \\
Cat & $46(3.54 \%)$ \\
Other animals & $18(1.39 \%)$ \\
Monkey & $10(0.77 \%)$ \\
\hline Total & $\mathbf{1 2 9 9 ( 1 0 0 \% )}$ \\
\hline $\mathrm{X}^{2}=0.83, \mathrm{p}=0.36 ; \mathrm{X}^{2}=5289.28, \mathrm{p}=0.001$
\end{tabular}

Age and sex distribution of patients with animal bites and scratches

Median age of all patients exposed to bites was 24.64 years ranging from 1 To 90 years old. Bites in ages from 5 to 25 years olds were found higher $(50.1 \%)$ than other age groups (Table 2). The ratio of male to female incurring bites was 3:1 and the differences noted were significant with sex $\left(\mathrm{X}^{2}=58.46, \mathrm{p}=0.001\right)$ and age groups $(\mathrm{F}=5.41, \mathrm{p}=0.02)$.
Table 2: Sex and age distribution of humans with animal bites and/or scratches in Addis Ababa for September 2008 to August 2009.

\begin{tabular}{ll}
\hline Sex/age(years) & \multicolumn{1}{c}{$\begin{array}{c}\text { Bite and/or } \\
\text { scratch } \\
\text { No. (\%) }\end{array}$} \\
\hline $\begin{array}{l}\text { Sex }{ }^{\mathrm{a}} \\
\text { Male }\end{array}$ & $727(55.97 \%)$ \\
Female & $572(44.03 \%)$ \\
Age (years) & \\
$<5$ & $62(4.77 \%)$ \\
$5-15$ & $314(24.17 \%)$ \\
$15-25$ & $337(25.94 \%)$ \\
$25-35$ & $235(18.09 \%)$ \\
$35-65$ & $279(21.47 \%)$ \\
$>65$ & $72(5.54 \%)$ \\
\hline${ }^{\mathrm{a}} \mathrm{X}^{2}=58.46, \mathrm{p}=0.001 ;$ & $\mathrm{D}=5.41, \mathrm{p}=0.020$.
\end{tabular}

Body parts affected with bites by main animal species The feet and hands were the most frequently affected body parts followed by multiple site bites of same and other body parts (Table 3).

Table 3: Humans' body parts affected by bites by main domestic species in Addis Ababa during September 2008 to August 2009.

\begin{tabular}{|c|c|c|c|c|c|c|}
\hline \multirow{2}{*}{$\begin{array}{l}\text { Animal } \\
\text { kind }\end{array}$} & \multicolumn{6}{|c|}{ Number of affected human cases (\%) } \\
\hline & Foot & Hand & Multiple site & $\begin{array}{l}\text { Other body } \\
\text { part }\end{array}$ & $\begin{array}{l}\text { Above neck } \\
\text { and at back }\end{array}$ & Total \\
\hline Dog & $681(55.6 \%)$ & $324(26.45 \%)$ & $92(7.51 \%)$ & $70(5.71 \%)$ & $58(4.73 \%)$ & 1225 \\
\hline Cat & 18 & 21 & 3 & 3 & 1 & 46 \\
\hline $\begin{array}{l}\text { Other } \\
\text { animals }\end{array}$ & 16 & 0 & 2 & 0 & 0 & 18 \\
\hline Monkey & 5 & 3 & 0 & 1 & 1 & 10 \\
\hline Total & 720 & 348 & 97 & 74 & 60 & 1299 \\
\hline
\end{tabular}

\section{Discussion}

The present study showed that animal bite and/or scratch was a common occurrence in human beings and dogs contributed the highest biting rate followed by cats and other animals like donkeys, horses, hyenas and cows. The least responsible were monkeys. This finding is in agreement with several studies that indicated dogs as the primary animal species implicated in bite injuries ranging from $63-80 \%$ (7). Similarly, the second bite is reported as made by cats with a range of $5-25 \%$ (8). In other reports, the most prominent injuries were by dogs $(30 \%)$ followed by horses $(22 \%)$ and cattle (12\%) (9). Animal related injuries may show differences arising from variation in behaviors, socioeconomic and epidemiological situations. For instance, insect bites were higher $(49 \%)$ followed by dog bites $(15 \%)$ and cats $(13.5 \%)$ in Poland (1). Similarly, insects (53\%), mammals $(31 \%)$ and marine animals $(7 \%)$ were reported in Italy as common sources of animal bite (10). In Khuzestan, dogs constitute $70 \%$ of all animal bite, nearly
$12 \%$ are scorpion stings and about $9 \%$ were mouse bites while the remaining $9 \%$ were caused by other animals such as cats and snakes (11).

In our study, animals cause a considerable percentage of the injuries in male than female and in young adults. Similarly, child predominance of $59 \%$ were reported and bite on male is two times more than females were reported $(9,10)$. Similar findings were reported by Hon et al., 2007. Higher dog attacks in children are thought to be attributable to their size and the proximity of their face to the dogs' mouth, and these attacks are generally related to the children's interaction with the dog, possibly provoking the attack (13). In addition, female adults were reportedly more attacked by cats than male adults (8).

The majority of bites were on legs followed by hand, multiple body parts and other body parts and the least was on the neck and at the back. This finding is in agreement with the report of Hon et al., 2007 (58.05\%) 
attacks were on legs and $30.65 \%$ on hands. Attempts at using, the foot and hand to avoid animal bite may be the possible reason for these parts being affected more. The other thought is that animals may be at ease to attack moving body parts.

\section{Conclusion}

The majority of bites in Addis Ababa were made by dogs with higher rate by stray dogs. To reduce the problem of dog bite a preventable public education is suggested.

\section{References}

1. Nogalski A, Jankiewicz L, Cwik G, Karski J, Matuszewski, L. Animal related injuries treated at the department of trauma and emergency medicine, Medical University of Lublin. Ann Agric Environ Med 2007; 14:57-61.

2. WHO in the Eastern Mediterranean Region. Annual Report of Eastern Mediterranean Regional Office. Alexandria: World Health Organization; 2003.

3. Deaver BV, Baker MD, Gloster RC, Grant WA, Harris JM, Hart BL. A community approach to dog bite prevention, JAMA. 2001; 218:1732-44.

4. Mode NA, Hackett EJ, Conway GA. Unique occupational hazards of Alaska: Animal related injuries. Wilderness Environ Med 2005; 16:185-191.

5. Ali A, Mengistu F, Hussen, K, Getahun, G, Deressa A, Yimer E, Tafese K. Overview of rabies in and around Addis Ababa, in Animals examined in EHNRI Zoonoses Laboratory between, 2003 and 2009. Ethiop Vet J 2010; 14(2):91-101.
6. Steele MT, Ma OJ, Nakase J, Moran GJ, Mower WR, Ong S, Krishnadasan A, Talan DA. Emergency ID NET Study Group: Epidemiology of animal exposures presenting to emergency departments. Acad Emerg Med 2007; 14(5):398-403.

7. ONeil ME, Mack KA, Gilchrist J. Epidemiology of non canine bite and sting injuries treated in U. S. emergency departments, 2001-2004. Public Health Rep 2007; 122(6):764-775.

8. Mucahit Emet, Nazim Ercument Beyhun, Zahide Kosan, Sahin Aslan, Mustafa Uzkeser, Zeynep Gokcen Cakir. Animal-related injuries: Epidemiological and meteorological features. Ann. Agric Environ Med 2009;16:87-92.

9. Massari M, Masini L. Relationships among injuries treated in emergency departments that are caused by different kinds of animals: epidemiological features. Eur J Emerg Med 2006;13(3):160-164.

10. Alavi SM and Alavi, L. Ten year's survey of animal bites in Khuzestan. Pak J Med Sci 2009;25(3):370374.

11. Hon KL, Fu CC, Chor CM, Tang PS, Leung TF, Man CY. Issues associated with dog bite injuries in children and adolescents assessed at the emergency department. Pediator Emerg Care 2007;23(7):445-9.

12. Mac Bean CE, Taylor DM, Ashby K. Animal and human bite injuries in Victoria: 1998-2004. Med $J$ Aust 2007;186:38-40.

13. Ozanne-Smith J, Ashby K, Stathakis VZ. Dog bite and injury prevention-analysis, critical review, and research agenda. In J Prev 2001;(7):321-326. 